\title{
Experimental Investigation of Pipeline In-Service Welding Process
}

\author{
Dr.Karima E. Amori, *Dr. Mohammad N. Hussain** and Hadeel B. Hilal* \\ *University of Baghdad/ Mech. Eng. Dept. \\ **Petroleum Research \& Development Center (PRDC).
}

\begin{abstract}
$\underline{\text { Abstract }}$
Welding of pipeline in active operation (called in-service welding) is an advanced technique employed to repair pipelines to safe transmission of petroleum or gas. A thermal experimental study is accomplished on welding process of gas pipeline in this work. An experimental setup had been designed, manufactured and instrumented to estimate the method for repairing locally pipelines defects (such as cracks and holes wall surface) under the influence of internal pressure. Also the thermal history of welding process was investigated experimentally to three cases which are : traditional welding process with no fluid flows inside the test pipe, an in-service welding process considering air as the flowing fluid inside test pipe, and an in-service welding process considering the liquefied petroleum gas (LPG) as flowing fluid inside test pipe. Results show that direct deposition of welding metal on a through hole under the influence of internal pressure succeeded for flow rate less than (12lpm) and failed for flow equal or higher than $(12 \mathrm{lpm})$ in which a sleeve repair is considered. The calculations are followed by a separate thermal stress analysis based on the thermal history.
\end{abstract}

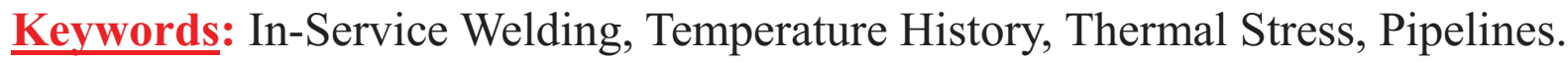

\section{Introduction}

In long-distance pipelines, defects can occur as a result of construction faults, corrosion, third party interference, and ground movement [1,2]. When a segment of pipeline is found to be corroded or local damaged, one of the conventional repair methods is that the sections of the pipeline would have to be sealed and degassed before any welding process and then purged before reinstatement. However, the cost is high in terms of venting and stopping the interior media supply. In addition, some of interior fluid leaks into the atmosphere which are wasteful and also environmentally damaging actions [3,4]. Welding onto a pipeline in active operation called in-service welding, it is an advance technique employed to repair, modify or extened of 
pipelines. These methods are widely used in guaranteeing the safe transmission of petroleum and natural gas. There is two concerns during in-service welding the first one is the possibility of burn-through during the welding process which is due to the localized heating, leading to the loss of material strength on the inner surface of the main pipe. The pipe wall may burst under internal pressure if the loss of the strength is significant. The second concern is the high cooling rate of the weldment or quick removal of heat from the pipe wall as a result of forced convection due to the fluid flow through the main pipe. The high cooling rate can promote the formation brittle phases at the of heat affecting zone (HAZ) with high hardness making the weldment susceptible to cracking therefore, by implementing proper heat input and appropriate in-service welding procedure optimal (HAZ) hardness can be obtained with low risk of burn-through. In 1992, Goldak et al. [5] applied a more general 3D finite element to calculate the thermal fields for circumferential fillet and direct-branch welds. They found that the assumed weld bead size and shape of the fillet weld had a significant influence on the calculated penetration and temperature profile around the weld pool. In 2011, Tao et al. [6] studied the burn-through phenomenon by analyzing radial displacement in the thickness of pipe wall by using numerical simulation software SYSWELD. In 2012, Gülşah Özişk et al. [7] presented the effect of heat source moving periodically on a circular steel pipe heated partly from its outer surface under stagnant ambient conditions. They found that the increasing in the thermal conductivity and the thickness of heat source reduce the temperature gradients and effective thermal stress ratio in a mount of (35$40 \%)$.

The objective of this work is to investigate experimentally the temperature distribution near the weld metal and estimate the method for repairing locally the defects in pipelines under fully operation .

\section{Experimental Apparatus and Procedure}

\subsection{Experimental setup :}

The experimental rig consist of a compressor (or gas bottles for LPG experimental tests), test section, cooling system and burner (for LPG experimental tests).

A compressor type Balma 150 compressor which is compress to (10 bar) as maximum is used to supply air to the rig. It is used in the tests were air is considered as the flowing gas. The compressor power is (1.5-2.2 KW), Whereas Gas Bottles were used in the tests in which LPG is considered as flowing fluid inside test pipe. They used to storage and provide the liquefied petroleum gas (LPG) which is a mixture of propan and butan. 
The Test Section was a low carbon steel pipe with $(101.6 \mathrm{~mm})$ inside diameter, $(6 \mathrm{~mm})$ wall thickness and $(1800 \mathrm{~mm})$ in length. The pipe receives gas or air from the gas bottles or compressor respectively and discharges it to the burner or environment. A defect which is representing by a hole of $(4 \mathrm{~mm})$ in diameter is machined in the test pipe and then it is cleaning by alcohol and then welded in order to make the experimental tests. The chemical composition, mechanical and thermal properties of pipe are shown in table (1). A Cooling System was also used in the experimental rig which is consists of three parts the first one is the Cooling coil which is made of copper pipe of diameter $(9.525 \mathrm{~mm})$. It designed according to the equation :

$$
\mathrm{L}=\mathrm{N} \sqrt{(2 \pi r)^{2}+\mathrm{P}^{2}}
$$

where $\mathrm{L}$ denotes coil length, $\mathrm{N}$ is the number of turns, $\mathrm{r}$ is the coil radius, $\mathrm{P}$ is the pitch. It is used to cool the test pipe to decrease the temperature of the gas so it will cool the molten pool during the process of welding. The second part is the Pump which is used for pumping the water through the cooling coil from the tank. The head of the pump is $(9-12 \mathrm{~m})$. The operating voltage required is $(220 \mathrm{~V})$ and the current is ( $2.5 \mathrm{Amp})$. The third part is a galvanized water storage of dimension $\left(500 * 500 * 500 \mathrm{~mm}^{3}\right)$ with a thickness of $(1.8 \mathrm{~mm})$ is used to supply the water to the pump.

A burner was used to burn the gas exits from the test pipe in order to prevent the pollution of air. This component used only in the tests in which LPG is considered as flowing gas. The BX1 series AC arc welding machine was used in the welding process which is a kind of $\mathrm{AC}$ arc welding power supply.

Thermocouples type $(\mathrm{k})$ are used to measure the temperatures at a selected points. Type (k) thermocouple consists of chromel -alumel with a sensitivity of $\left(41 \mu \mathrm{V} / \mathrm{C}^{\circ}\right)$ and temperature range of $\left(-200 \mathrm{C}^{\circ}\right.$ to $\left.+1350 \mathrm{C}^{\circ}\right)$. The thermocouples connected to the data logger which records the temperatures varying with time and save them in an SD card in the form of excel sheet. The data logger used consists of 12 channels temperature recorder. The pressure transducer type DRUCK LTD S/N 18770 of ( 0 to 5000 mbar) range with pressure indicator is used in order to show the pressure value. Two pressure transducer were used to measure the inlet and outlet pressure of test pipe. A flow meter with a reader is used in order to measure the rate of air or gas flowing through the test pipe which is installed at the test pipe inlet. The flow meter and reader used is S-meter TFB-100 which is designed for LPG in liquid phase. The flow rate rang is (0.04$0.25 \mathrm{~m}^{3} / \mathrm{h}$ of liquid LPG) with measurement accuracy of $( \pm 0.5 \%)$. Figure(3). Shows experimental rig. 


\subsection{Experimental work:}

The experimental work consists of three parts including : traditional welding process with no fluid flows inside test pipe, an in-service welding process considering air as the flowing fluid inside test pipe, and an in-service welding process considering the Liquefied Petroleum Gas (LPG) as flowing fluid inside test pipe. The current, voltage and welding speed applied were (94 Ampere, 58 Volte , and $2.5 \mathrm{~mm} / \mathrm{s}$ ). The welding electrode dimensions were (3.2 in diameter and $350 \mathrm{~mm}$ in length). Fig. 1 shows experimental parts.

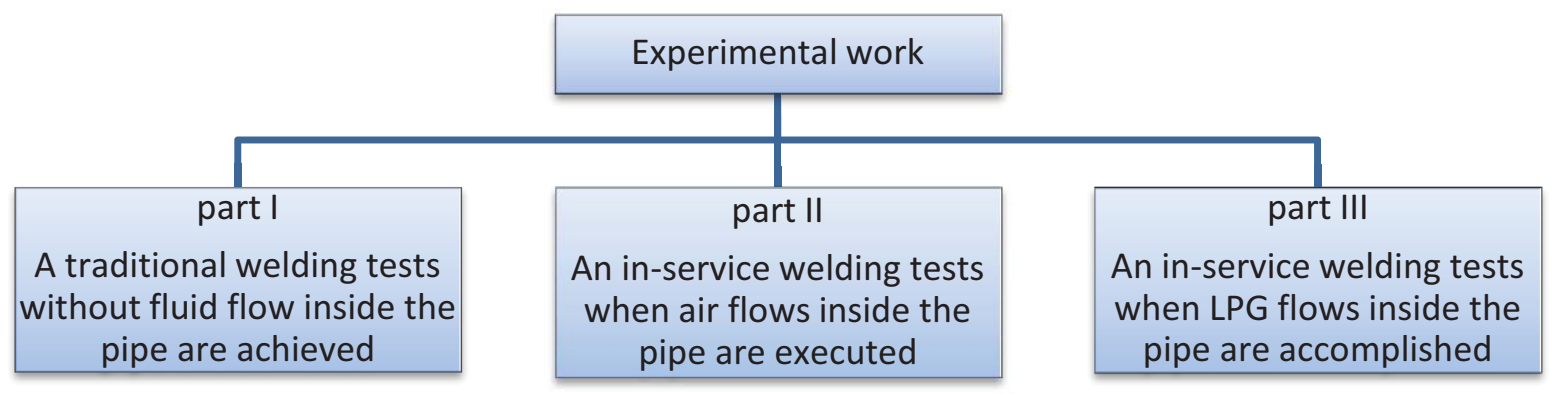

Fig.(1) Experimental Work Parts

\section{Theory :}

Thermal stresses can be calculated from the following equation:

$\tau_{\text {thermal }}=\alpha \mathrm{E} \Delta \mathrm{T}$

where $\tau_{\text {thermal }}$ denotes thermal stress in $\mathrm{Pa}, \mathrm{E}$ the modulus of elasticity $=210 \mathrm{GPa}, \alpha$ the Coefficient of thermal expansion $=11.8 \times 10^{-6} \mathrm{~cm} / \mathrm{cm} /{ }^{\circ} \mathrm{C}$.

\section{Error analysis :}

when $\mathrm{T}=810^{\circ} \mathrm{C}, \mathrm{T}_{\text {ambient }}=25^{\circ} \mathrm{C}$ the thermal stress is equal to :

$\tau=11.8 \times 10^{-6} \times 210 \times 10^{9} \times(810-25)=1945230000 \mathrm{~Pa}$

The thermal stress $\left(\tau_{\text {thermal }}\right)$ is a function of different variable according to equation (2).

The following table shows accuracy of parameters used in the calculation of the error analysis.

\begin{tabular}{|c|c|c|c|}
\hline Independent variable & Temperature & Thermal expansion & Modulus of elasticity \\
\hline Uncertainty interval & $\pm 0.1^{\circ} \mathrm{C}$ & $\pm 0.1 \times 10^{-6} \mathrm{~cm} / \mathrm{cm}^{\circ} \mathrm{C}$ & $\pm 0.1 \times 10^{9} \mathrm{~Pa}$ \\
\hline
\end{tabular}

Based on the error analysis presented in [8], the percentage error is calculated as:

$\mathrm{w}_{\mathrm{R}}=\left[\left(\frac{\partial \mathrm{R}}{\partial \mathrm{x}_{1}} \mathrm{w}_{1}\right)^{2}+\left(\frac{\partial \mathrm{R}}{\partial \mathrm{x}_{2}} \mathrm{w}_{2}\right)^{2}+\cdots+\left(\frac{\partial \mathrm{R}}{\partial \mathrm{x}_{\mathrm{n}}} \mathrm{w}_{\mathrm{n}}\right)^{2}\right]^{1 / 2}$ 
$\mathrm{w}_{\tau}=\left[\left(\frac{\partial \tau}{\partial \Delta \mathrm{T}} \mathrm{w}_{\Delta \mathrm{T}}\right)^{2}+\left(\frac{\partial \tau}{\partial \alpha} \mathrm{w}_{\alpha}\right)^{2}+\left(\frac{\partial \tau}{\partial \mathrm{E}} \mathrm{W}_{\mathrm{E}}\right)^{2}\right]^{1 / 2}$

where $w_{R}$ is the uncertainty in the results and $w_{1}, w_{2}$ and $\ldots w_{n}$ are the uncertainty in the independent variables.

$\frac{\partial \tau}{\partial \Delta \mathrm{T}}=\alpha \mathrm{E}=11.8 \times 10^{-6} \times 210 \times 10^{9}=2478000$

$\frac{\partial \tau}{\partial \alpha}=\mathrm{E} \Delta \mathrm{T}=210 \times 10^{9} \times(810-25)=1.6485 \times 10^{14}$

$\frac{\partial \tau}{\partial \mathrm{E}}=\alpha \Delta \mathrm{T}=11.8 \times 10^{-6} \times(810-25)=0.009263$

$\mathrm{w}_{\tau}=\left[(2478000 \times 0.1)^{2}+\left(1.6485 \times 10^{14} \times 0.1 \times 10^{-6}\right)^{2}+\left(0.009263 \times 0.1 \times 10^{9}\right)^{2}\right]^{1 / 2}$

$\mathrm{w}_{\tau}=16512863.52 \mathrm{~Pa}$

$\frac{\mathrm{w}_{\tau}}{\tau}=0.848 \%$

\section{Results and discussion}

The first part includes a traditional welding process for a sleeve extracted from the test pipe with (101.6 mm inside diameter and $75 * 75 \mathrm{~mm}^{2}$ dimensions) to repair a through hole of ( $4 \mathrm{~mm}$ in diameter) enclosed by a gummy material on the tested pipe without flowing fluid inside it. The thermocouples have been installed over the sleeve surface and beside it on the surface of the tested pipe as shown in figure( $3 \& 4)$ a illustrates the temperature history for the nodes on the right side of the welding line and fig. $4 \mathrm{~b}$ illustrates temperature history for the nodes on the left side of the welding line. If the average temperature of the left and right three point considered separately, it can be observed that the average temperature will increase from nodes (1 and 1') to nodes $\left(2,2^{\prime}\right.$ and $\left.3,3^{\prime}\right)$ that is according to the fluidity of the melted metal because of the curvature of the test pipe so there will be an accumulative heating results a temperature rising. The figure shows that maximum temperature is $\left(814{ }^{\circ} \mathrm{C}\right)$ at time $(11-12 \mathrm{~s})$ belong to node $(2)$ and $\left(308^{\circ} \mathrm{C}\right.$ ) for node $2^{\prime}$. The difference between the maximum temperature for nodes on right (node 2) and left (node 2') of the welding line is according to the oscillating welding electrode movement (wave technique). Fig. 7a and b shows stress history for nodes (1, 2, and 3) and (1', 2', and $\left.3^{\prime}\right)$ respectively in which the maximum stress is $\left(19.789 * 10^{8} \mathrm{pa}\right)$ at time $(11-12 \mathrm{~s})$ belong to node (2).

The second part includes an in-service welding process considering air as the fluid flow inside the test pipe for two cases:

Case I : Welding a through holes of $(4 \mathrm{~mm})$ in diameter with different air flow rate $(3,6,9$ and 12 $\mathrm{lpm}$ ) to study the possibility of direct weld deposit on the defect under the influence of internal pressure (which is related to flow rate variation). The thermocouples are fixed around the hole as shown in fig. 2. Table (2) explain the results for the tests including through hole with flow rate 
equal to $(3,6,9$, and $12 \mathrm{lpm})$. It is found that the repair welding process success when the flow rate is equal to $(3,6,9 \mathrm{lpm})$ and failed when the flow rate equal or higher than $(12 \mathrm{lpm})$ because the strength of the melted metal cannot resist the internal pressure and that lead to leak continua. So another method was adopted to decrease air discharging from the hole and then welding the hole. This method was to close the hole with a gummy material sustain a high temperature approximately $\left(500^{\circ} \mathrm{C}\right)$ this material stopped the leak completely but the direct weld failed because of the heterogeneity in properties between the material of the test pipe and gummy material.

Case II : welding a sleeve extracted from the test pipe with $(101.6 \mathrm{~mm}$ inside diameter and $75 * 75 \mathrm{~mm}^{2}$ dimensions) to repair a through hole of ( $4 \mathrm{~mm}$ in diameter) enclosed by a gummy material on tested pipe for flow rate equal or higher than $(12 \mathrm{lpm})$. The thermocouples have been installed over the sleeve surface and beside it on the surface of the tested pipe as shown in fig. 3 . Fig. $5 \mathrm{a}$ and $\mathrm{b}$ illustrate the temperature history for the nodes on the right and left sides of the welding line respectively with air flow rate equal to $(48 \mathrm{lpm})$. The figure reports that maximum temperature is $\left(300^{\circ} \mathrm{C}\right)$ at time (32-34 s) belong to node (3). Fig. 8a and b show stress history for nodes $(1,2$, and 3$)$ and $\left(1^{\prime}, 2^{\prime}\right.$, and $\left.3^{\prime}\right)$ in which the maximum stress is $\left(6.9632 * 10^{8}\right.$ pa) at time (32-34 s) belongs to node (1) that is according to the oscillating electrode movement.

The third part includes an in-service welding process for a sleeve extracted from the test pipe with (101.6 mm inside diameter and $75 * 75 \mathrm{~mm}^{2}$ dimensions) to repair a through hole of ( $4 \mathrm{~mm}$ in diameter) filled with a gummy material on tested pipe considering LPG as the flowing fluid inside it. The gas flow rate was (48 lpm). The thermocouples have been installed over the sleeve surface and beside it on the surface of the tested pipe as shown in fig. 3. Fig. 6a and b illustrate The temperature history of different locations for this test. The figure explain that maximum temperature is $\left(914^{\circ} \mathrm{C}\right)$ at time $(24-25 \mathrm{~s})$ belong to node (1). The temperature of nodes $(1,2,3$, and 4$)$ are more than that for nodes $\left(1^{\prime}, 2^{\prime}, 3^{\prime}\right.$, and $\left.4^{\prime}\right)$ respectively which explains that the nodes close to the sleeve on the test pipe (near the welding seam) are more thermally affected with the welding heat flux. Figure $9 \mathrm{a}$ and $\mathrm{b}$ shows stress history for nodes $(1,2$, and 3$)$ and (1', $2^{\prime}$, and $\left.3^{\prime}\right)$ respectively in which the maximum stress is $\left(21.906 * 10^{8} \mathrm{pa}\right)$ at time $(24-25 \mathrm{~s})$ belong to node (1).

\section{Conclusions}

An experimental setup had been designed, manufactured and instrumented to estimate the repair method of defects under the influence of a type of flowing fluid and internal pressure. The 
thermal history and thermal stress history of in-service welding process were also investigated. It is found that direct deposition of weld metal on a through hole under the influence of internal pressure for applied current of (94 Ampere and 57 Volt) success for flow rate less than (12 lpm) and failed when the flow is equal or higher than (12 lpm) in which a sleeve repair is considered. During in-service welding, the flowing air will take away much of the heat, which accelerate cooling rate of the welding zone. It was concluded that burn-through do not occur in the experiment simulation for in-service welding because of the influence of flowing fluid inside the test pipe.

Table (1) The Chemical Composition of the Test Pipe Material

\begin{tabular}{|c|c|c|c|}
\hline Elements & Sample & Elements & Sample \\
\hline $\mathrm{C} \%$ & 0.141 & $\mathrm{~V} \%$ & Less than 0.0005 \\
\hline $\mathrm{Si} \%$ & 0.293 & $\mathrm{~W} \%$ & Less than 0.005 \\
\hline $\mathrm{Mn} \%$ & 1.13 & $\mathrm{Ta} \%$ & 0.019 \\
\hline $\mathrm{P} \%$ & 0.006 & $\mathrm{Sn} \%$ & 0.003 \\
\hline $\mathrm{S} \%$ & 0.004 & $\mathrm{Zr} \%$ & 0.003 \\
\hline $\mathrm{Cr} \%$ & 0.024 & $\mathrm{Zn} \%$ & Less than 0.0005 \\
\hline $\mathrm{Mo} \%$ & Less than 0.001 & $\mathrm{Bi} \%$ & Less than 0.0015 \\
\hline $\mathrm{Ni} \%$ & 0.017 & $\mathrm{As} \%$ & Less than 0.0005 \\
\hline $\mathrm{Al} \%$ & Less than 0.001 & $\mathrm{~Pb} \%$ & Less than 0.001 \\
\hline $\mathrm{Co} \%$ & Less than 0.001 & $\mathrm{Se} \%$ & Less than 0.001 \\
\hline $\mathrm{Cu} \%$ & 0.023 & $\mathrm{Sb} \%$ & 0.020 \\
\hline $\mathrm{Nb} \%$ & Less than 0.001 & $\mathrm{Fe} \%$ & المتبقي \\
\hline $\mathrm{Ti} \%$ & 0.002 & & \\
\hline
\end{tabular}

Table (2) Results of Direct Deposition of Weld Metal on a Through Hole when Air is considered as Flowing Fluid inside Test Pipe

\begin{tabular}{|c|c|c|c|c|}
\hline No. & Flow rate $(\mathrm{lpm})$ & $\mathrm{T} \max \left({ }^{\circ} \mathrm{C}\right)$ & $\mathrm{T} \max$ period $(\mathrm{s})$ & Cooling time (s) \\
\hline 1 & 3 & 530.5 & 3 & 50 \\
\hline 2 & 6 & 1180 & 3 & 37 \\
\hline 3 & 9 & 618.9 & 2 & 29 \\
\hline 4 & 12 & 473.1 & 3 & \\
\hline
\end{tabular}




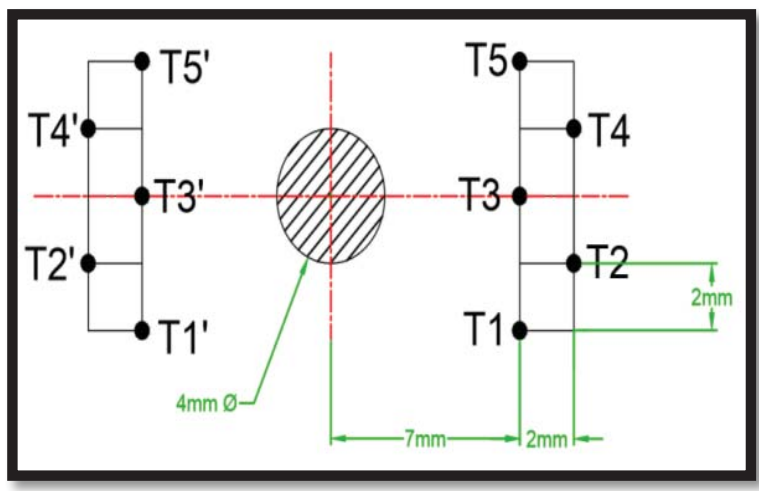

(a)

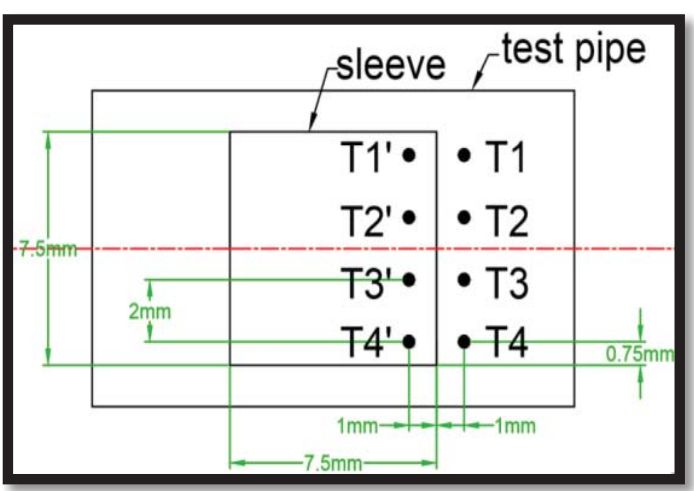

(b)

Fig. (2) Thermocouples Locations, (a) According to the Through Hole, (b) According to the Sleeve

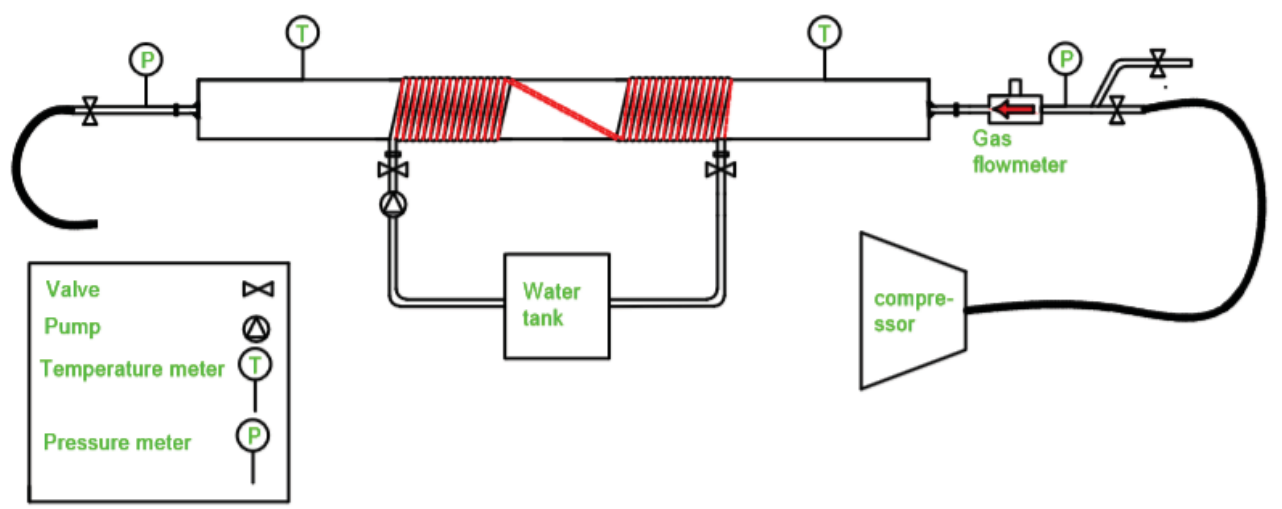

(a)

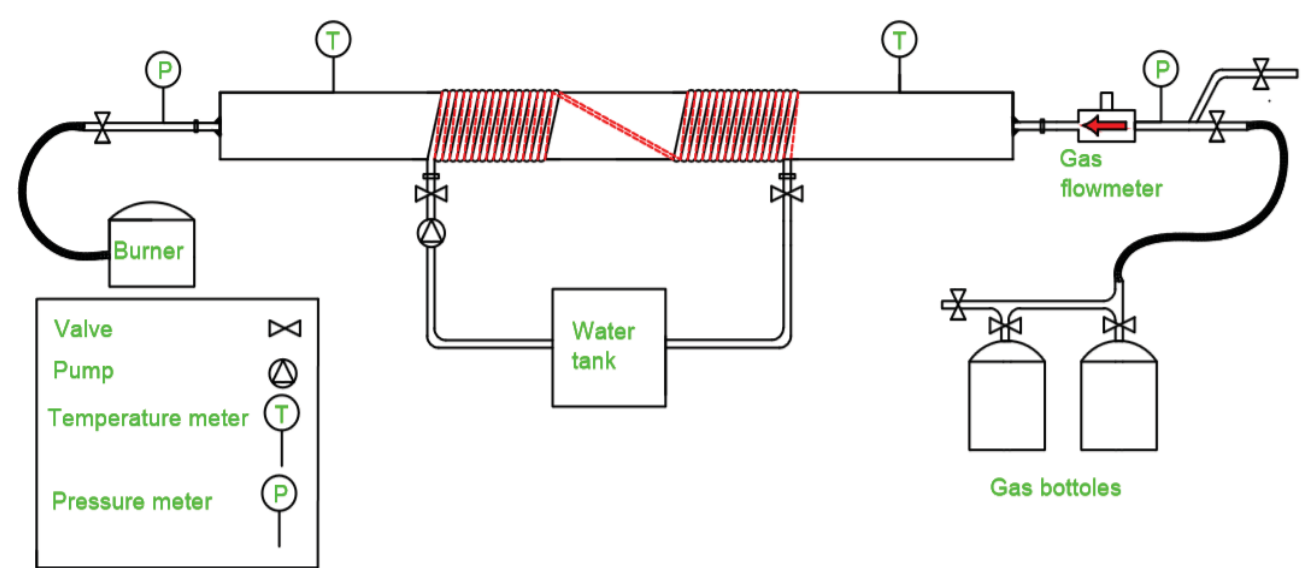

(b)

Fig . (3) Experimental Rig, (a) Air Tests, (b) LPG Tests 

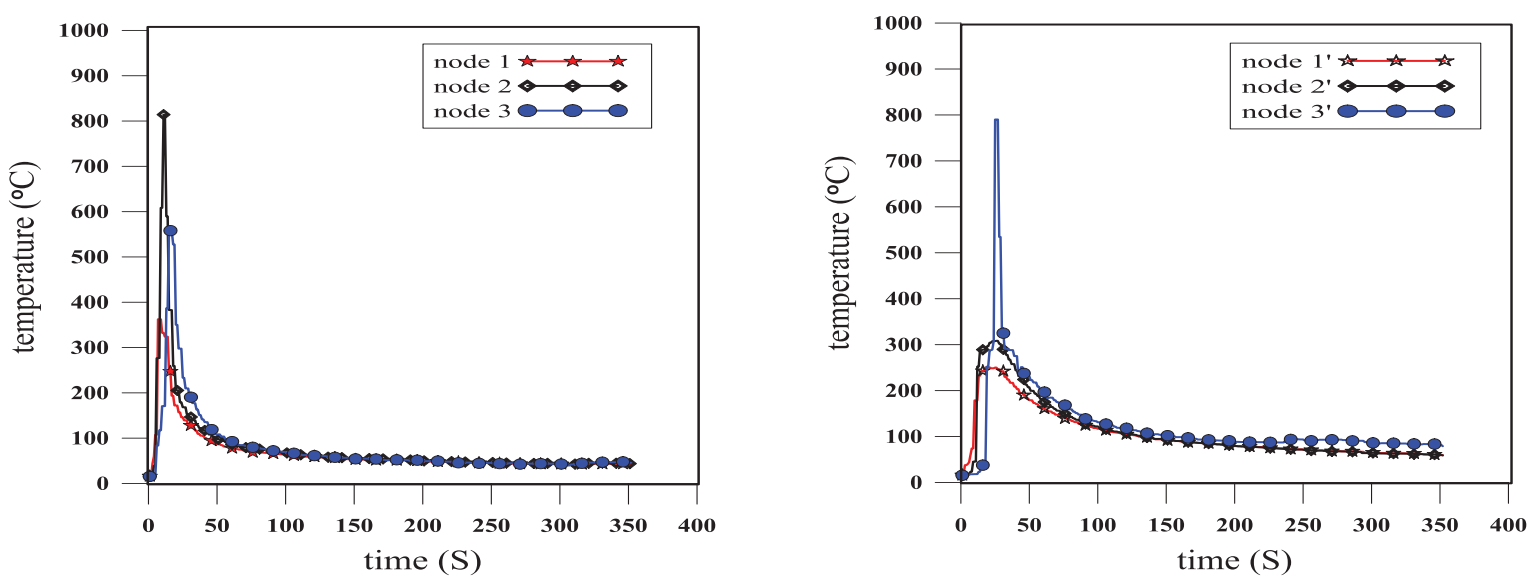

Fig.(4) Comparison between Temperature History for the traditional welding process for sleeve on a part of pipe,a) 1,2 and 3, b) $1^{\prime}, 2^{\prime}$ and $3^{\prime}$
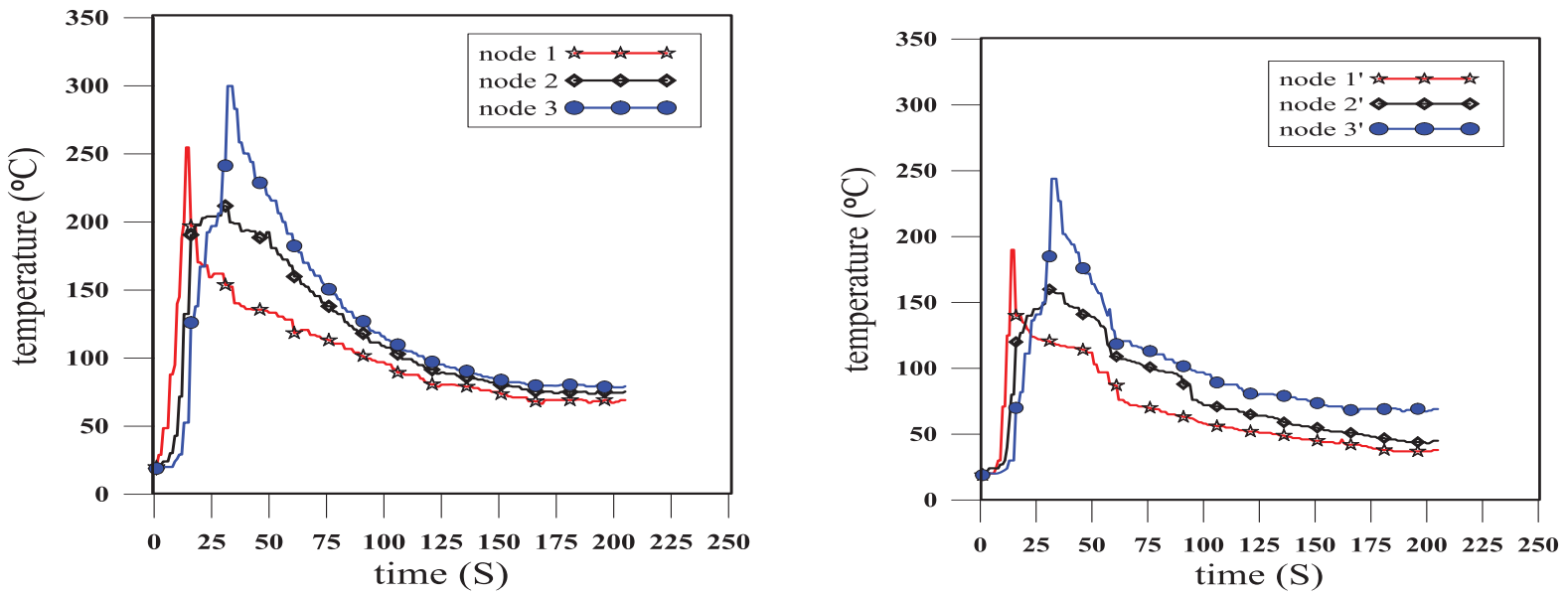

Fig. (5) Comparison between Temperature History for in-service welding process for sleeve with air flowing fluid,a) 1, 2 and 3, b) 1', 2' and 3'
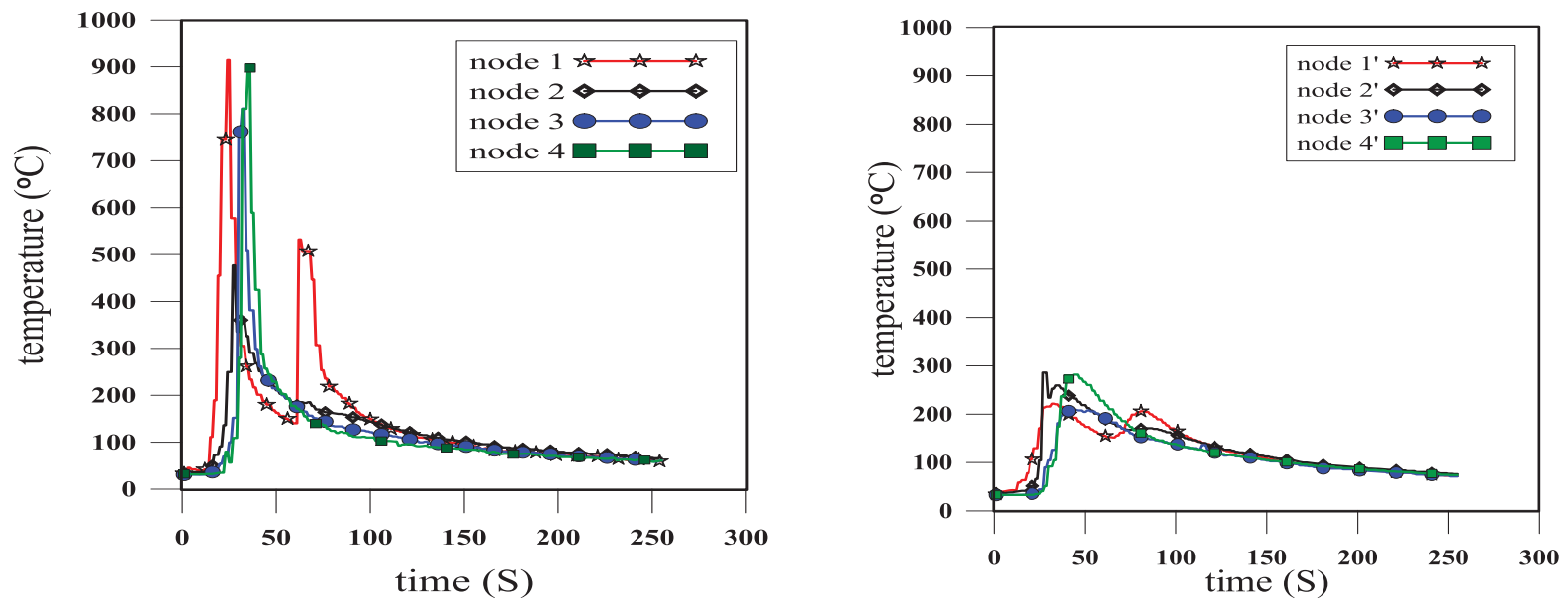

Fig. (6) Comparison between Temperature History for in-service welding process for sleeve with LPG flowing fluid,a) 1,2, 3 and 4, ,b) $1^{\prime}, 2^{\prime}, 3^{\prime}$ and $4^{\prime}$ 

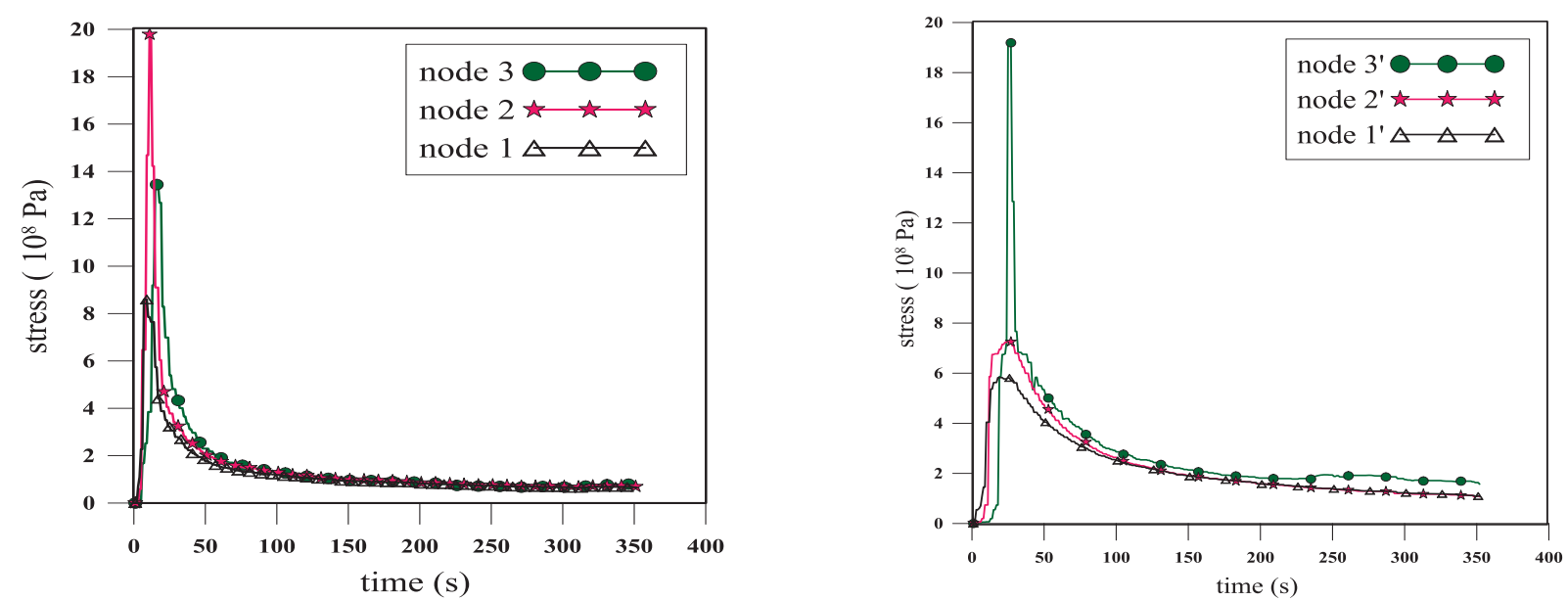

Fig. (7) Comparison between Stress History of Traditional Welding Process for Sleeve on Test Pipe with no Fluid Flows inside it,a) 1, 2 and 3, b) 1', 2' and 3'
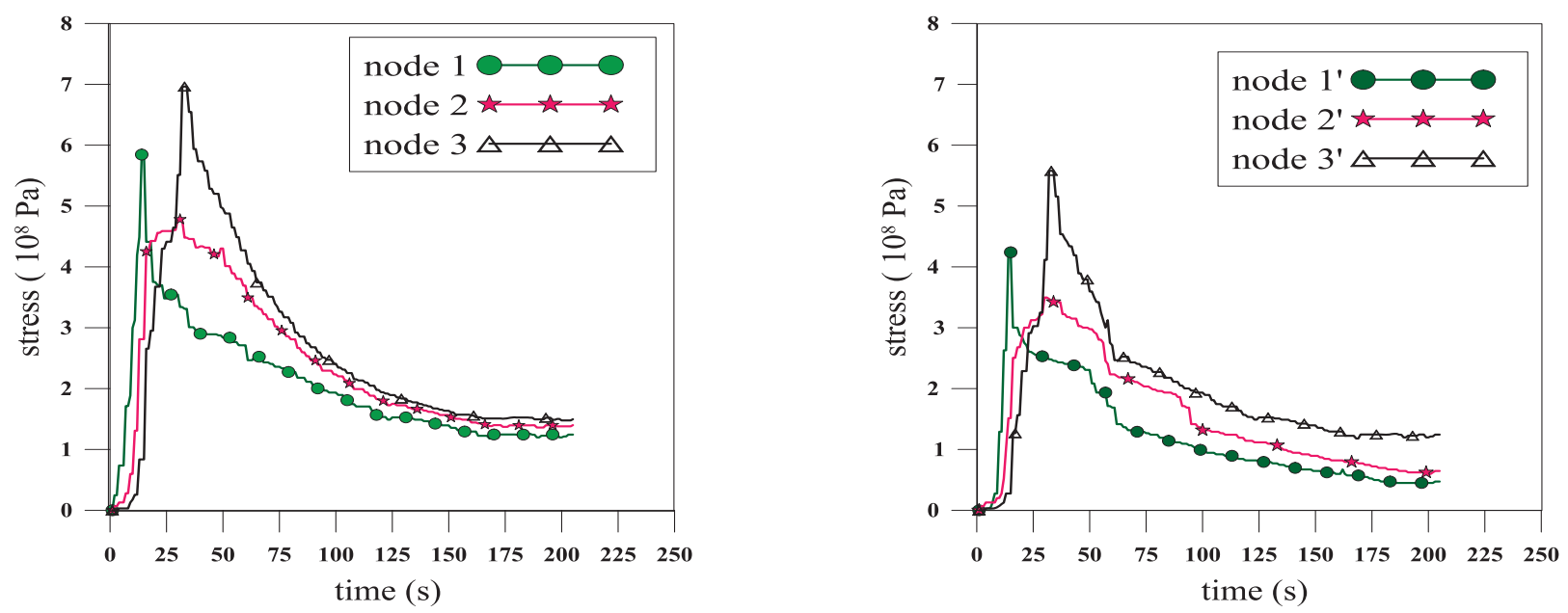

Fig. (8) Comparison between Stress History of In-Service Welding Process for Sleeve on Test Pipe with Air Flows inside it,a) 1,2 and 3 ,b) 1',2' and 3'
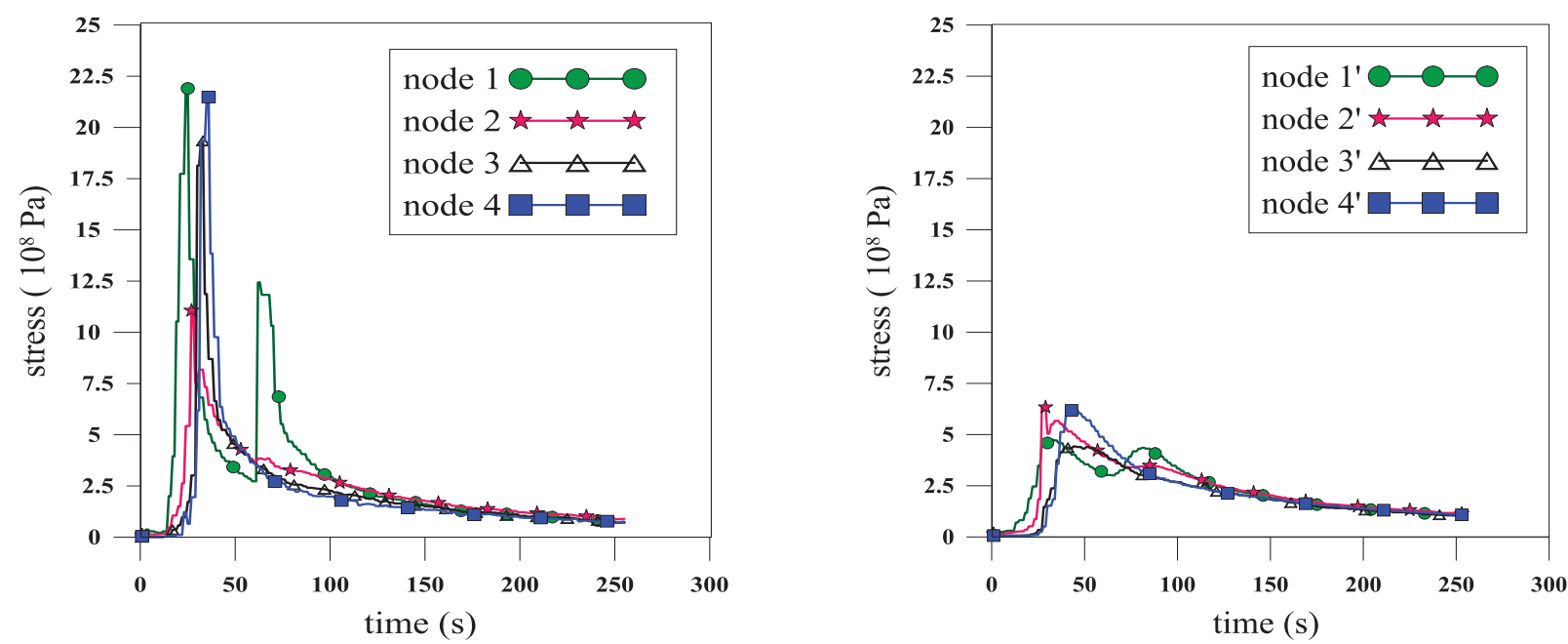

Fig. (9) Comparison between Stress History of In-Service Welding Process for Sleeve with LPG Flows inside it,a) 1, 2, 3 and 4, b) 1', 2', 3' and 4' 


\section{References}

1. M.A. Wahab, P.N Sabapathy and M.J. painter, "The onset of pipe wall failure during in-service welding of gas pipeline", J. of material processing technology. 168,pp. 414-442, (2005).

2. P.N. Sabapathy , M.A. Wahab' ,M.J. Painter, " the prediction of burn-through during in-service welding of gas pipelines", International journal of pressure vessels and piping, Vol.77, pp.669677, (2000).

3. P.N. Sabapathy, M.A. Wahab' ,M.J. Painter, "numerical models of in-service welding of gas pipelines", J Mater Process Technol 2001;118:14-21.

4. Hamed Masumi Asl and Ali vatani, "numerical analysis of the burn-through at in-service welding of 316 stainless steel pipeline", Int. J. of pressure vessels and piping, Vol. 105-106, pp. 49-59, (2013).

5. J.A. Goldak, A.S. Oddy, D.V. Dorling, Finite Element Analysis of Welding on Fluid Filled, Pressurized Pipelines, ASM International, USA, 1993, pp.45-50.

6. Tao HAN, Yong WANG and LIU, "study on burn through prediction of in-service welding", J. of transaction of JWRI, pp. 9-12, (2011).

7. Gülşah Özişk M. Serdar Genç and Hüseyin Yapici, "Transient thermal stress distribution in a circular pipe heated externally with a periodically moving heat source", Int. J. of pressure vessel and piping, Vol. 99-100, pp.9-22, (2012).

8. Holman J.P., Heat Transfer, Fifth Edition McGraw- Hill, (1989).

9. Ivan Samardžić, Marko Dunđer, Zvonimir Kolumbić, “Arc Welding of Steel Pipe Connection on Steel Gas Pipeline in-service". 